\title{
Autoria negra: percursos contemporâneos - Entrevistas
}

\author{
Por Graziele Frederico, ${ }^{1}$ Lúcia Tormin Mollo ${ }^{2}$ e Paula Queiroz Dutra ${ }^{3}$
}

Entre o racismo estrutural e a permanência do discurso da "democracia racial", as populações negras buscam construir formas de falar de si e do mundo. Nas últimas duas décadas, verificou-se um aumento de visibilidade da representação negra na sociedade brasileira - seja nos meios de comunicação de massa, seja nas artes, na música e na literatura, seja no campo acadêmico - e seu caráter "marginal" diante das formas de expressão dominantes vem sendo fortemente questionado.

No dia $1^{\circ}$ de junho de 2016, realizou-se na Universidade de Brasília a III Jornada Literária de Autoria Negra: Percursos Contemporâneos, organizada pelo Grupo de Estudos em Literatura Brasileira Contemporânea, coordenado pela prof ${ }^{a} \mathrm{dr}^{\mathrm{a}}$ Regina Dalcastagnè. ${ }^{4}$ Com o propósito de estabelecer um diálogo entre a crescente produção literária de escritoras e escritores negros e a universidade, a jornada tornou-se um espaço para discussão de temas fundamentais do mundo contemporâneo: o racismo e o sexismo ainda tão presentes em nossa sociedade; os problemas de perspectiva, de linguagem, de gênero; e, principalmente, da produção e recepção dessa produção de autoria negra, que vem questionando intensamente a falta de espaço para sua divulgação no mercado editorial brasileiro.

Do referido encontro, que reuniu grandes nomes da literatura de autoria negra brasileira, surgiu a vontade de organizar um conjunto de entrevistas que registrassem um pouco das muitas ricas conversas estabelecidas durante (mas não apenas) a jornada literária. São registros do que inspira e motiva esses autores e autoras a escrever, do que os inquieta e desperta para o texto literário, mas são, acima de

\footnotetext{
${ }^{1}$ Doutoranda em Literatura na Universidade de Brasília (UnB), Brasília, DF, Brasil. E-mail: grafrederico@gmail.com

2 Doutoranda em Literatura na Universidade de Brasília (UnB), Brasília, DF, Brasil. E-mail: ltorminmollo@gmail.com

${ }^{3}$ Doutoranda em Literatura na Universidade de Brasília (UnB), Brasília, DF, Brasil. E-mail: qpaulad@gmail.com

${ }^{4}$ Para mais informações sobre o evento, acesse: https://www.gelbc.com/jornadaautorianegra
} 
tudo, a sua visão de mundo, tão indispensável a todos e a todas que pretendem compreender e apreciar melhor a produção literária brasileira contemporânea. Esperamos, com esse dossiê, que cada uma dessas conversas enriqueça o repertório de autores e autoras a serem lidos e estudados.

Recebido em 15 de fevereiro de 2017. Aprovado em 7 de abril de 2017.

\section{resumo/abstract/resumen}

\section{Autoria negra: percursos contemporâneos}

Graziele Frederico

Lúcia Tormin Mollo

Paula Queiroz Dutra

Este dossiê reúne uma série de entrevistas realizadas com autores/as negros/as em junho de 2016. Os autores e as autoras aqui presentes são: Cristiane Sobral, Cuti, Dinha, Eliane Marques, Mel Adún, Esmeralda Ribeiro, Miriam Alves, Ronald Augusto, Lívia Natália, Ricardo Aleixo e Ana Maria Gonçalves. As entrevistas tematizam a relação dos/as autores/as com a literatura, a questão do rótulo "literatura negra", o preconceito e os problemas políticos e sociais do nosso tempo.

Palavras-chave: autoria negra, preconceito, literatura brasileira contemporânea.

\section{Black authorship: contemporary paths}

Graziele Frederico

Lúcia Tormin Mollo

Paula Queiroz Dutra

This dossier brings together a series of interviews with black authors conducted in June of 2016. The authors presented here are: Cristiane Sobral, Cuti, Dinha, Eliane Marques, Mel Duarte, Esmeralda Ribeiro, Miriam Alves, Ronald Augusto, Livia Natalia, Ricardo Aleixo and Ana Maria Gonçalves. The interviews broach the authors' relationship with literature, the meaning of the term "black literature", prejudice and the political and social problems of our time.

Keywords: black authorship, prejudice, contemporary Brazilian literature. 


\section{Autoría negra: caminos contemporáneos}

Graziele Frederico

Lúcia Tormin Mollo

Paula Queiroz Dutra

Éste dossier recoge una serie de entrevistas llevadas a cabo en junio de 2016 con autores/as negros/as. Los autores y las autoras presentadas aquí son: Cristiane Sobral, Cuti, Dinha, Eliane Marques, Mel Adún, Esmeralda Ribeiro, Miriam Alves, Ronald Augusto, Livia Natalia, Ricardo Aleixo y Ana Maria Gonçalves. Las entrevistas tematizan la relación del autor con la literatura, la cuestión de la etiqueta "literatura negra", el prejuicio y los problemas políticos y sociales de nuestro tiempo.

Palabras clave: autoría negro, prejuicio, literatura brasileña contemporánea. 